\title{
A review of silicon carbide development in MEMS applications
}

\author{
Liudi Jiang* \\ School of Engineering Sciences, \\ University of Southampton, \\ Highfield, Southampton SO17 1BJ, UK \\ E-mail: L.Jiang@soton.ac.uk \\ ${ }^{*}$ Corresponding author

\section{Rebecca Cheung} \\ School of Engineering and Electronics, \\ Scottish Microelectronics Centre, \\ University of Edinburgh, \\ King's Buildings, West Mains Road, \\ Edinburgh EH9 3JF, UK \\ E-mail: Rebecca.Cheung@ee.ed.ac.uk
}

\begin{abstract}
Due to its desirable material properties, Silicon Carbide (SiC) has become an alternative material to replace $\mathrm{Si}$ for Microelectromechanical Systems (MEMS) applications in harsh environments. To promote SiC MEMS development towards future cost-effective products, main technology areas in material deposition and processes have attracted significant interest. The developments in these areas have contributed to the rapid emergence of $\mathrm{SiC}$ MEMS prototypes. In this paper, we give an overview of the important developments in $\mathrm{SiC}$ material formation and fabrication processes in recent years. Some of the most interesting state-of-the-art SiC MEMS devices are reviewed. This highlights the major progresses in SiC MEMS developed thus far. This paper also looks into the prospect of SiC MEMS drawing attention to potential issues.
\end{abstract}

Keywords: SiC; silicon carbide; MEMS; microelectromechanical systems; review; deposition; fabrication; devices; prospect.

Reference to this paper should be made as follows: Jiang, L. and Cheung, R. (2009) 'A review of silicon carbide development in MEMS applications', Int. J. Computational Materials Science and Surface Engineering, Vol. 2, Nos. 3/4, pp.225-240.

Biographical notes: Liudi Jiang received her $\mathrm{PhD}$ from the University of Dundee, UK in 2001. She has then worked for over three years as a Research Fellow at the Scottish Microelectronics Centre, University of Edinburgh, where she was a key contributor to research aiming towards the optimisation of $\mathrm{SiC}$ dry etch processes and the development of state-of-the-art $\mathrm{SiC}$ Microelectromechanical Systems (MEMS). She is currently a Research Council UK (Roberts) Academic Fellow at the School of Engineering Sciences, University of Southampton, Southampton, UK. Her current research focuses on the development of micro/nanoelectromechanical systems from novel materials with a view to explore their applications in various engineering systems. 
She also works on developing innovative processes for the next generation micro/nanoelectromechanical systems. She has so far published over 30 high standard papers in international journals and has two patent applications pending.

Rebecca Cheung is a Professor within the Institute of Integrated Micro and Nano Systems in the School of Engineering and Electronics at the University of Edinburgh, and present research interests lie in MEMS and nanoelectronics. Previously, worked on various topics related to semiconductor technology, nanoelectronics, mesoscopic physics and microwave circuits; in Delft Institute of Microelectronics and Submicron Technology, The Netherlands; Laboratory for Electromagnetic Fields and Microwave Electronics, ETHZ, Switzerland and the University of Canterbury, New Zealand.

\section{Introduction}

Since its inception in the late 1960s (Nathanson et al., 1967), Microelectromechanical Systems (MEMS) have become an important area of technology combining material, mechanical, electrical, chemical, optical and fluids engineering disciplines. They allow interrelated device components to be integrated into comprehensive systems at very small scales which complete functions such as sensing and actuating. Building on the well-established techniques from the microelectronics industry over the past 50 years, MEMS have attracted considerable interest worldwide, which has led to rapid developments especially over the past decade. The total MEMS global market already exceeds $\$ 10$ billion, up from $\$ 100$ million only five years ago (Hensler, 2002). The primary material used in MEMS remains Si. Although Si MEMS can draw upon microfabrication techniques ready established in the microelectronics industry, due to its material properties, it is not suitable for MEMS operating in severe conditions such as high temperatures $\left(>300^{\circ} \mathrm{C}\right)$. However, there remains an increasing demand for sensors and actuators for harsh environment applications such as devices in combustion processes, gas turbine control and oil industry, which has stimulated the search for alternatives to $\mathrm{Si}$. As a result, Silicon Carbide $(\mathrm{SiC})$ has been recognised as an excellent candidate for microsensor and microactuator applications in harsh environments due to its unique properties which include high hardness and wear resistivity, good thermal conductivity and chemical inertness. Table 1 shows the basic material properties of $\mathrm{SiC}$ in comparison to those of $\mathrm{Si}$ and GaAs conventional semiconductors.

The field of SiC MEMS is still in its infancy and occupies a niche market. Capturing a large percentage of the total MEMS market requires substantial research to address challenges in many aspects in relation to SiC MEMS developments. Since Cree Research Inc. became the first supplier of $\mathrm{SiC}$ substrates in 1987, single crystal $\mathrm{SiC}$ wafers have been commercially available. However, from a product development point of view, the development of larger-area substrates at lower costs is still required. In comparison, large-area Si wafers can already be produced with high volume and at low unit cost. In recent years, epitaxial grown single and polycrystalline $\mathrm{SiC}$ layers on $\mathrm{Si}$ or $\mathrm{SOI}$ wafers have shown advantages in the realisation of cost-effective SiC MEMS devices. This has stimulated research on $\mathrm{SiC}$ layer deposition and characterisation. Furthermore, there is limited knowledge in many essential areas of SiC MEMS such as etching, doping, oxidation and contact metallisation. Therefore, research activity thus far has focused on 
these areas with a view to the development of efficient micromachining processes. With the development in $\mathrm{SiC}$ material and fabrication processes, new SiC MEMS device prototypes have been rapidly emerging which could potentially have a strong impact to the overall MEMS market.

Table 1 SiC material properties in comparison to those of $\mathrm{Si}$ and GaAs

\begin{tabular}{llll}
\hline Properties & $3 C-\mathrm{SiC}(6 \mathrm{H}-\mathrm{SiC})$ & $\mathrm{Si}$ & $\mathrm{GaAs}$ \\
\hline Lattice constant $(\AA)$ & $4.36\left(\mathrm{a}_{0}: 3.08 ; \mathrm{C}_{0}: 15.12\right)$ & 5.43 & 5.65325 \\
Band gap $(\mathrm{eV})$ & $2.36(3)$ & 1.12 & 1.4 \\
Density $\left(\mathrm{g} / \mathrm{cm}^{3}\right)$ & 3.21 & 2.33 & 5.32 \\
Melting point $\left({ }^{\circ} \mathrm{C}\right)$ & Sublimes at $T>3100$ & 1410 & 1240 \\
Thermal conductivity $(\mathrm{W} / \mathrm{cm} \mathrm{K})$ & 4.9 & 1.5 & 0.55 \\
Linear thermal expansion coeff. $\left(10^{-6} \mathrm{~K}^{-1}\right)$ & $2.9(4.2)$ & 2.6 & 5.73 \\
Young's modulus $(\mathrm{GPa})$ & $392-694$ & $130-185$ & 85.5 \\
Physical stability & Excellent & Good & Fair \\
Electron mobility $\left(\mathrm{cm}^{2} / \mathrm{V} \mathrm{s}\right)$ & $1000(400)$ & 1500 & 8500 \\
Hole mobility $\left(\mathrm{cm}^{2} / \mathrm{V} \mathrm{s}\right)$ & $40(50)$ & 450 & 400 \\
Breakdown field $\left(10^{6} \mathrm{~V} / \mathrm{cm}\right)$ & 4 & 0.3 & 0.4 \\
\hline
\end{tabular}

Focusing on recent progresses, this paper gives a brief overview of SiC MEMS development in terms of achievements and challenges. In the remainder of this paper, Chemical Vapour Deposition (CVD) as a main deposition technique for SiC MEMS is reviewed in Section 2. Microfabrication methods associated with SiC MEMS are summarised in Section 3. The key microfabrication step of dry etching of SiC and its recent development are set out in this section. The wide range of applications and reported examples of up-to-date SiC MEMS devices are given in Section 4. In particular, $\mathrm{SiC}$ resonators and sensors as well as $\mathrm{SiC}$ coated MEMS are described. Finally, Section 5 looks to the future of SiC MEMS highlighting issues still requiring attention.

\section{Chemical vapour deposition of $\mathrm{SiC}$}

$\mathrm{SiC}$ is the only known binary compound of $\mathrm{Si}$ and $\mathrm{C}$ and exhibits a one-dimensional polymorphism called polytypism. A large number of $\mathrm{SiC}$ polytypes exist, which are distinguished by differences in the stacking sequence of the identical planes of Si and $\mathrm{C}$ atoms. In the $\mathrm{SiC}$ polytypes, the basic structural unit consists of a primarily covalently bonded ( $88 \%$ covalent and $12 \%$ ionic) tetrahedron of four $\mathrm{C}$ atoms with a $\mathrm{Si}$ atom at the centre (or four $\mathrm{Si}$ atoms with a $\mathrm{C}$ atom at the centre) (Park, 1998) as shown in Figure 1. Main $\mathrm{SiC}$ polytypes that are commercially available and relevant to $\mathrm{SiC}$ device applications are $4 \mathrm{H}-, 6 \mathrm{H}-$ and $3 \mathrm{C}-\mathrm{SiC}$. Hexagonal $4 \mathrm{H}-$ and $6 \mathrm{H}-\mathrm{SiC}$ bulk substrates have been used to fabricate pressure (Okojie et al., 1998) and acceleration (Okojie et al., 2001) sensors through bulk micromachining processes. $3 \mathrm{C}-\mathrm{SiC}$ is the only $\mathrm{SiC}$ polytype that can be synthesised on Si substrates which enables deposition on large-area substrates. Therefore, in the last few years, $3 \mathrm{C}-\mathrm{SiC}$ as the dominant polytype for MEMS applications has attracted most of the attention. In addition, due to the preservation of 
many desirable properties, amorphous $\mathrm{SiC}(\mathrm{a}-\mathrm{SiC})$ is a particularly attractive material for devices where low deposition temperature is necessary. Among the available techniques developed thus far, CVD techniques are widely used in 3C- and a-SiC formation and are reviewed in the following sections.

Figure 1 A SiC unit cell

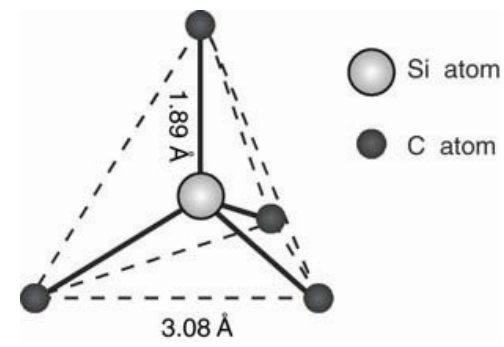

\subsection{Atmospheric pressure chemical vapour deposition}

Atmospheric Pressure Chemical Vapour Deposition (APCVD) was one of the first techniques developed to deposit SiC. A typical APCVD reactor is comprised of a cooled wall chamber, reactive gas inlet, exhaust port, a substrate susceptor centrally positioned in the reactor chamber and heating coils (Zorman et al., 2006). During the deposition, a carbonisation process (Nishino et al., 1983; Powell et al., 1987; Zorman et al., 1995) is initially applied to a clean $\mathrm{Si}$ surface, followed by $\mathrm{SiC}$ growth using $\mathrm{Si}$ and $\mathrm{C}$ containing precursors. SiC growth rate up to several microns per hour can be achieved with the potential to be doped into $N$ and $P$ types. An APCVD system is relatively simple and easy-to-setup due to the incorporation with few temperature sensitive components. Both epitaxial and polycrystalline 3C-SiC can be deposited by APCVD. It is particularly advantageous for $\mathrm{SiC}$ epitaxy, where higher temperatures $\left(1300^{\circ} \mathrm{C}\right)$ are typically required for single crystalline $\mathrm{SiC}$ grown on $\mathrm{Si}$ substrates. Due to mismatches in thermal expansion coefficients and lattice constants, residual stress often exists in these epitaxial layers. Figure 2 shows a typical TEM results obtained from an epitaxial 3C-SiC film by APCVD. The deposited films are particularly suitable for single crystalline 3C-SiC MEMS structures fabricated through $\mathrm{Si}$ bulk micromachining such as membranes (Mitchell et al., 2003) and piezoresistive pressure sensors (Zorman et al., 2006).

Figure 2 (a) High-resolution TEM image of the SiC/Si interface and (b) cross-sectional TEM diffraction pattern of the $\mathrm{SiC} / \mathrm{Si}$ interface

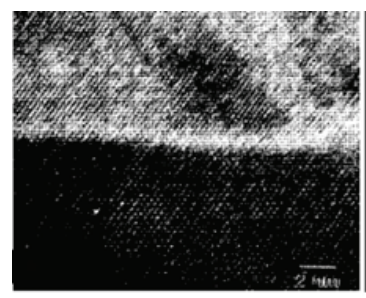

(a)

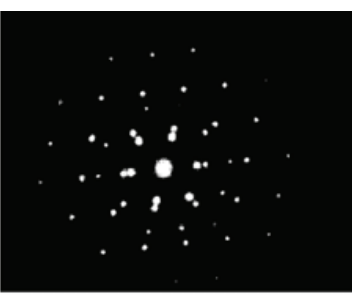

(a)

Source: Reused with permission from Zorman et al. (1995). Copyright 1995, American Institute of Physics. 


\subsection{Low pressure chemical vapour deposition}

A typical Low Pressure Chemical Vapour Deposition (LPCVD) system usually consists of a reactor chamber, gas inlet, vacuum system and heating element using induction, resistive or IR lamp heating. Although film growth rate is much lower than that in APCVD processes, more substrates can generally be accommodated in LPCVD especially when resistive heating is used. Zorman et al. (2002) recently reported a unique LPCVD furnace capable of holding up to $150 \mathrm{~mm}$-diameter substrates. Due to the vacuum system involved and lower chamber pressure, compared to APCVD, LPCVD allows exploiting more varieties of precursors as well as reducing the incorporation of impurities in the deposited films. Therefore, in general, the process generates higher quality $\mathrm{SiC}$ films with much better uniformity across large substrate areas. Epitaxial 3C-SiC film has also been grown on Si wafers by LPCVD and its membrane structures (Krotz et al., 1995) showed much better performance at higher pressure and elevated temperatures comparing with their Si counterparts. In recent years, LPCVD has become a leading technique for polycrystalline $3 \mathrm{C}-\mathrm{SiC}$ films which can be deposited on various substrates including $\mathrm{SiO}_{2}$ and $\mathrm{Si}_{3} \mathrm{~N}_{4}$ and thus introduce great flexibility in SiC MEMS design and fabrication. As an important factor affecting MEMS performance, residual stress in the films from LPCVD can be controlled by the deposition pressures. Doping can also be achieved in situ by adding dopants into the feed gas. Thus far, a number of precursors have been explored for SiC LPCVD processes (Boo et al., 2000; Chen et al., 2000; Clavaguera-Mora et al., 1997; Hurtos and Rodriguez-Viejo, 2000; Lee et al., 2001). In particular, Stoldt et al. (2001, 2002) have developed a low temperature (800-1000 ${ }^{\circ} \mathrm{C}$ ) process to deposit polycrystalline 3C-SiC films for MEMS applications utilising 1,3-Disilabutane (DSB) as precursor. Controlled nitrogen doping is also demonstrated (Wijesundara et al., 2002) at $850^{\circ} \mathrm{C}$ by the addition of $\mathrm{NH}_{3}$ to the feed gas, as shown in Figure 3. By varying Dichlorosilane (DCS) and 1,3-DSB fractions in the inlet gas mixture, this group also reported (Roper et al., 2006) that the residual stress and strain gradient of polycrystalline $\mathrm{SiC}$ films can be tuned, which is demonstrated by the bending of the subsequently fabricated cantilever beams in Figure 4.

Figure 3 The resistivity and the conductivity of the cubic-SiC films as a function of percentage of $\mathrm{NH}_{3}$ gas in the feed gas

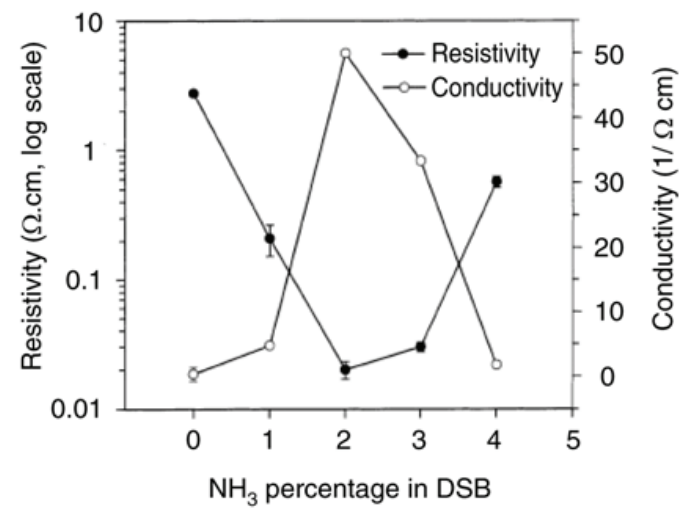

Source: Reprinted from Wijesundara et al. (2002). Copyright 2002, with permission from Elsevier. 
Figure 4 SEM of the SiC cantilever beam array for films deposited with (a) no DCS, (b) $20 \mathrm{sccm}$ DCS and (c) $40 \mathrm{sccm}$ DCS

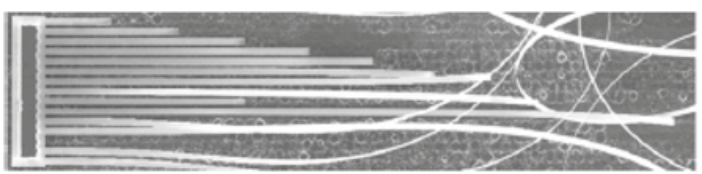

(a)

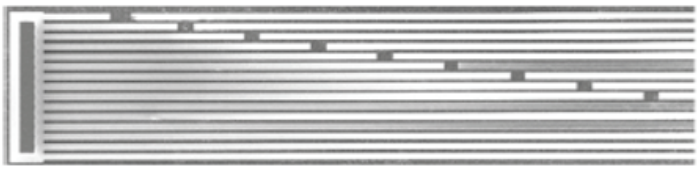

(b)

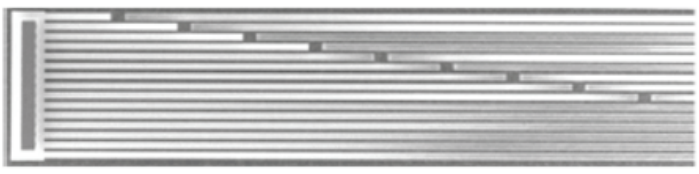

(c)

Source: Reprinted with permission from Roya Maboubian. (Roper et al., 2006).

Copyright 2006 Institute of Physics Publishing.

\subsection{Plasma enhanced chemical vapour deposition}

All the above mentioned CVD methods require reasonably high temperatures. In contrast, Plasma Enhanced Chemical Vapour Deposition (PECVD) allows SiC films to be deposited at much lower temperatures $\left(200-400^{\circ} \mathrm{C}\right)$. Commercially available PECVD systems can be utilised for the processes which is beneficial from future mass production point of view. The low deposition temperatures also suggest its potential suitability for IC compatible MEMS processing. Many $\mathrm{Si}$ and $\mathrm{C}$ containing gas precursors such as $\mathrm{SiH}_{4}$ and $\mathrm{CH}_{4}$ (Flannery et al., 1998; Sarro et al., 1998) as well as liquid source such as $\mathrm{C}_{6} \mathrm{H}_{18} \mathrm{Si}_{2}$ (hexamethyldisilane) (Klumpp et al., 1994) have been used to form a-SiC by PECVD. The as-deposited $\mathrm{SiC}$ films are amorphous and post-deposition annealing is required for crystallisation. The deposited a-SiC is usually employed as a coating material for various MEMS component (Flannery et al., 1998). Systematic research carried out by Sarro et al. (1998) has demonstrated that, using a high throughput PECVD system, it possible to control the stress in the deposited films by altering deposition parameters such as pressure and gas flow ratio. Both doped and undoped SiC can be obtained by PECVD. Due to the low temperature in the PECVD processes, it is feasible to deposit $\mathrm{SiC}$ on a variety of materials such as aluminium which is not possible in the APCVD and LPCVD processes. Figure 5 shows that using the same PECVD conditions, a-SiC can be deposited on patterned oxide, aluminium and polysilicon with reasonable conformal coverage. 
Figure 5 SEM micrographs illustrating the step coverage of PECVD SiC deposited on patterned (a) oxide, (b) aluminium and (c) polysilicon (see online version for colours)

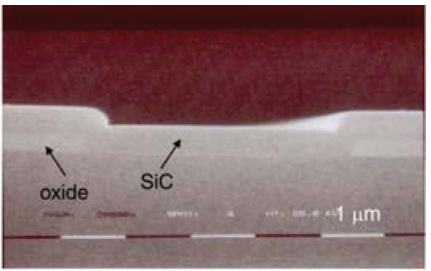

(a)

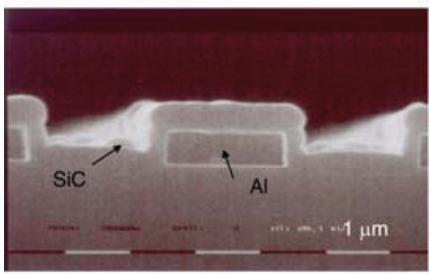

(b)

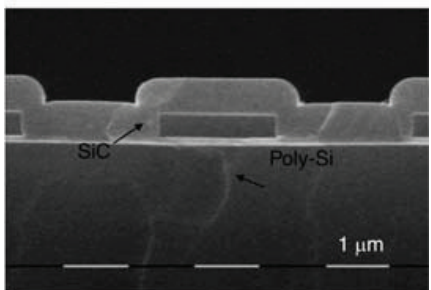

(c)

Source: Pictures courtesy of Sarro (2000). DIMES, Delft University of Technology, The Netherlands.

\section{Fabrication processes for SiC MEMS}

Effective fabrication routes play key roles in the realisation of reliable MEMS. The advanced physical and chemical properties of SiC form the cornerstone for SiC MEMS as well as the microfabrication challenges. Therefore, unlike well-established $\mathrm{Si}$ microfabrication processes, there is still a strong requirement of efficient and cost-effective micromachining techniques for SiC MEMS. Bulk and surface micromachining are the main fabrication routes for MEMS in general (Madou, 1997; Wise, 1998). Thus, their developments towards SiC MEMS are briefly reviewed in the subsections.

\section{$3.1 \quad$ Bulk micromachining}

It is generally difficult to perform bulk micromachining of $\mathrm{SiC}$ substrates because standard Si bulk micromachining techniques are not effective in SiC etching. Powerful techniques such as laser ablation (Dong et al., 2003) and focused ion beam sputtering (Bischoff et al., 2001) have been utilised for this purpose. A laser assisted 
photoelectrochemical etching technique has also been developed to fabricate a $6 \mathrm{H}-\mathrm{SiC}$ pressure sensor (Okojie et al., 1998). The ability to deposit 3C-SiC on Si substrates has made many devices possible by employing conventional Si bulk micromachining. In these processes, $\mathrm{SiC}$ has high etch resistance in most commonly used anisotropic etchants to remove the bulk silicon (KOH, TMAH or EDP solutions). Therefore, using bulk $\mathrm{Si}$ anisotropic etching as the final releasing step from the back of the wafer, a multitude of 3C-SiC structures, ranging from diaphragms, cantilever beams and torsional structures for mechanical property studies, to transmission windows for optical studies (Mehregany et al., 1997) have been realised. Alternatively, bulk Si anisotropic etching from the front of the wafer can also be exploited to achieve free standing $\mathrm{SiC}$ microstructures. In particular, when the starting material is thin $\mathrm{SiC}$ layer grown on top of Si wafer, a one-step process has been developed (Jiang et al., 2003a) to fabricate straight $\mathrm{SiC}$ resonators. In this case, using patterned $\mathrm{SiO}_{2}$ as etch mask, inductive coupled plasma using $\mathrm{SF}_{6} / \mathrm{O}_{2}$ gas mixture etches the $\mathrm{SiC}$ anisotropically followed by the bulk isotropic etching of the $\mathrm{Si}$ underneath from the front of the wafers which consequently frees the $\mathrm{SiC}$ beams. In addition, $\mathrm{SiC}$ can also be deposited into a $\mathrm{Si}$ mould precreated by deep reactive ion etching (Rajan et al., 1998), subsequently the MEMS devices can be realised by chemical mechanical polishing and release of the $\mathrm{SiC}$ structures by dissolving the Si mould.

\subsection{Surface micromachining}

Thin films of polycrystalline and amorphous $\mathrm{SiC}$ can be deposited on a variety of substrates which include thin layers of polySi, $\mathrm{SiO}_{2}$ and $\mathrm{Si}_{3} \mathrm{~N}_{4}$ on top of $\mathrm{Si}$ wafers. Using these multilayered structures, devices with thin $\mathrm{SiC}$ as structural material and polySi or $\mathrm{SiO}_{2}$ as sacrificial layers can be fabricated by surface micromachining processes. As the only practical way to pattern $\mathrm{SiC}$ for MEMS applications (Xie et al., 1995), plasma-based dry etching is a key process in $\mathrm{SiC}$ surface micromachining. Recent developments in this area are reviewed as follows.

Fluorine-based gas mixtures have been shown to be the most effective gas for $\mathrm{SiC}$ etching in terms of high etch rate. The F species in the plasma can react with both $\mathrm{Si}$ and $\mathrm{C}$ to form volatile compounds as reaction products. Commonly, $\mathrm{SF}_{6}$ and $\mathrm{O}_{2}$ gas mixtures are used because the optimum amount of $\mathrm{O}_{2}$ addition provides another pathway for volatilising $\mathrm{C}$ in the forms of $\mathrm{CO}, \mathrm{CO}_{2}$ (Flamm et al., 1981; Jiang et al., 2003b) and thereby increases etch rates. SiC etch rate of $1.05 \mu \mathrm{m} / \mathrm{min}$ (Khan et al., 2001) has been achieved in an inductively coupled plasma reactor using $\mathrm{SF}_{6}$ and $\mathrm{O}_{2}$ gas mixtures. However, obtainable $\mathrm{SiC}$ etch rates strongly depend on the plasma conditions used such as pressure, flow rate, chuck power, etc. Figure 6 (Jiang et al., 2003b) shows the SiC etch rate as a function of pressure at different chuck powers in an inductively coupled plasma chamber. Due to an ion induced etching mechanism, anisotropic etch profiles are often achieved, as shown in Figure 7 (Plank et al., 2003). The etch selectivities of SiC over metal mask materials such as $\mathrm{Ni}$ and $\mathrm{Al}$ are about 20 and 7, respectively, which are much higher than those of $\mathrm{SiC}$ over photoresists or dielectrics (Pearton, 2006). It is also worth mentioning here that chlorinated plasma has also been investigated (Jiang et al., 2004; Khan et al., 2001) because it induces little surface damage, although the etch rates are much lower. 
Figure $6 \mathrm{SiC}$ etch rate versus pressure at chuck power of 80,120 and $150 \mathrm{~W}$, respectively $\mathrm{SF}_{6}$ flow rate $=40 \mathrm{sccm}$ and $\mathrm{O}_{2}$ flow rate $=10 \mathrm{sccm}$

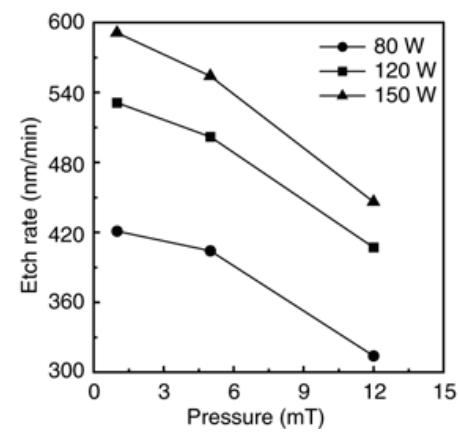

Source: Jiang et al. (2003b).

Figure 7 Anisotropic $\mathrm{SiC}$ etch profile

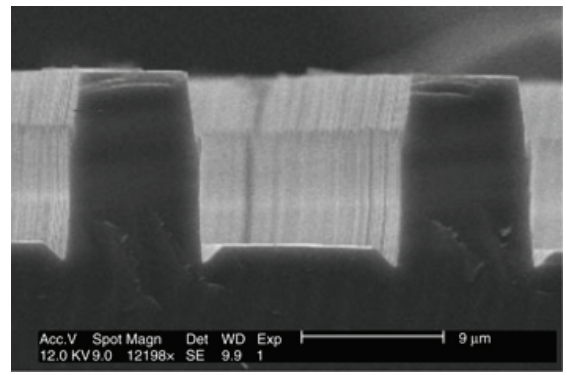

Source: Reprinted with permission from Plank et al. (2003). Copyright 2003, Institute of Physics Publishing.

\section{$4 \mathrm{SiC}$ in MEMS device applications}

The advancement of the material deposition techniques and fabrication processes for $\mathrm{SiC}$ has enabled the successful realisation of numerous SiC MEMS devices over the years. A few papers (Mehregany and Zorman, 1999; Sarro, 2000) and books (Cheung, 2006; Park, 1998) have given comprehensive and timely overviews in the past on the relevant development. This section focuses on the recent progress of some specific SiC-based MEMS devices. Since it is difficult to cover every device reported so far, the review focuses on some interesting development in application areas of $\mathrm{SiC}$ as resonators, sensors and MEMS coatings.

\subsection{SiC resonators}

SiC has larger ratio between Young's modulus and density $(E / \rho)$, which results in higher resonant frequencies with better quality factors for beam structures compared to their $\mathrm{Si}$ and GaAs counterparts (Yang et al., 2001). This is particularly beneficial for micromechanical resonators to be used as frequency filtering in high-performance communication transceivers (Nguyen, 1997), oscillators and high sensitivity sensing. 
$\mathrm{SiC}$ lateral resonators have been fabricated by surface micromachining and packaged for operations in high-temperatures environments (Roy et al., 2002). Recently, Jiang et al. have described the development of $\mathrm{SiC}$ resonator structures with mechanical (Jiang et al., 2003a), electrostatic (Jiang et al., 2005) and electrothermal actuations (Jiang et al., 2006), respectively. Simple cantilever and bridge beams have been designed and fabricated by bulk and surface micromachining processes. The basic structures are shown in Figure 8. Through mechanical actuation, the fundamental resonance frequencies $\left(f_{0}\right)$ have been identified to be between $120 \mathrm{KHz}$ and $5 \mathrm{MHz}$ depending on the beam geometry (Jiang et al., 2003a). A thin NiCr electrode is included on top of the beams and forms ohmic contact with $\mathrm{SiC}$. The resonators can then be electrostatically excited by applying a sinusoidal ac voltage $\left(V_{\mathrm{ac}}\right)$ at $f_{0}$ and $f_{0} / 2$ with a dc component $\left(V_{\mathrm{dc}}\right)$ between the top $\mathrm{NiCr} / \mathrm{SiC}$ and bottom bulk $\mathrm{Si}$ electrodes. The amplitude of the fundamental resonant peaks has been found to have a linear relation with the applied $V_{\mathrm{ac}}$ and $V_{\mathrm{dc}}$, respectively (Jiang et al., 2005). Furthermore, for the first time, SiC resonators with electrothermal actuation have also been reported. Electrothermal actuation is especially suitable for device applications requiring large displacement and high contact force. NiCr heating elements were patterned on top of the $\mathrm{SiC}$ beams (Figure 9) and electrothermal actuation was achieved by applying a combination of $V_{\mathrm{ac}}$ and $V_{\mathrm{dc}}$. It is also been found that, during electrothermal actuation, $f_{0}$ can be tuned by the applied $V_{\mathrm{dc}}$ (Figure 10) which could be potentially advantageous for the post-package fine tuning of the $\mathrm{SiC}$ resonators (Jiang et al., 2006). Lastly, the development of SiC nanomechanical resonators have been reported as a step towards SiC Nanoelectromechanical Systems (NEMS) devices (Yang et al., 2001). This could be beneficial for the development of future generations of RF devices and ultrasensitive sensors. It is worth noting that attention should be paid in NEMS because scale effects are likely to enter into the design and affect material issues within the devices (Spearing, 2000).

Figure 8 SEM images of a group of free standing (a) cantilever beams with lengths of 25, $50,100,150,200 \mu \mathrm{m}$, respectively and (b) bridges with lengths of 50, 100, 150, 200, $250 \mu \mathrm{m}$, respectively. All the beams are $15 \mu \mathrm{m}$ wide and nominally $2 \mu \mathrm{m}$ thick

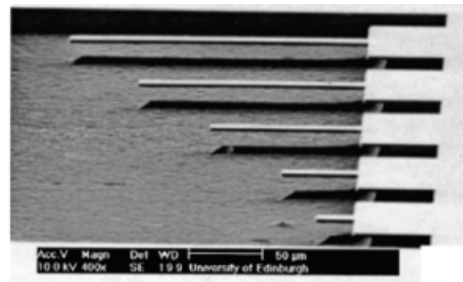

(a)

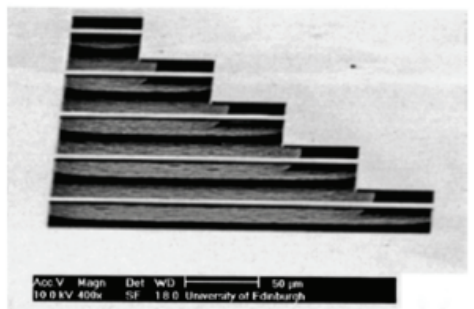

(b)

Source: Jiang et al. (2003a). 
Figure 9 SEM micrographs of the fabricated $\mathrm{NiCr} /$ polySiC cantilever. The inset shows the side view

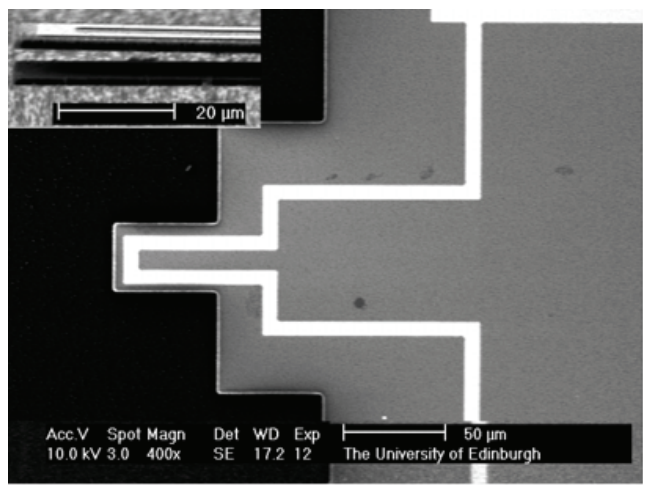

Source: Jiang et al. (2005).

Figure 10 The shift of the fundamental resonance frequency versus input $V_{\mathrm{dc}}\left(V_{\mathrm{ac}}=48 \mathrm{mV}_{\mathrm{pp}}\right)$ for an electrothermally actuated $\mathrm{NiCr} /$ polySiC cantilever

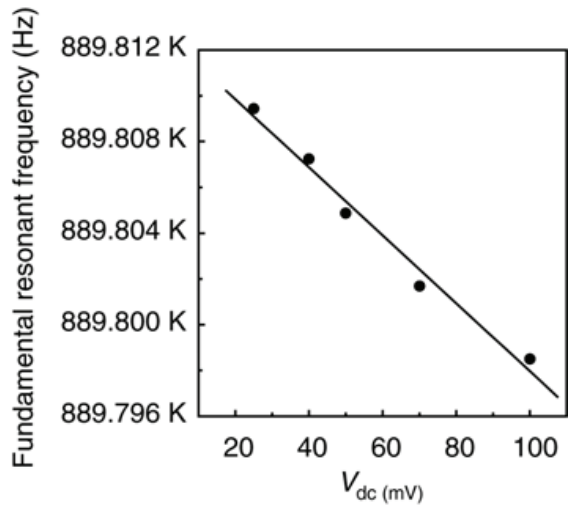

Source: Jiang et al. (2006).

\subsection{SiC sensors}

Advanced $\mathrm{SiC}$ sensor systems have been developed to detect pressure, acceleration, chemicals and even radiation. Among these, SiC pressure sensor application is one of the main application areas of SiC MEMS. It is particularly suitable for applications in high temperature, high pressure and vibration environments such as pressure sensors used in oil industry. A multitude of $\mathrm{SiC}$ pressure sensors have been reported (Pakula et al., 2003a,b; Zappe et al., 2001; Ziermann et al., 1999) over the years. Very recent research from $\mathrm{Wu}$ et al. demonstrated the development of diaphragm type pressure sensors based on polySiC and 3C-SiC piezoresistors (Wu et al., 2006). PolySiC diaphragm was used for the former with the polySiC piezoresistors doped by introducing dopant gas $\mathrm{PH}_{3}$ during APCVD, while Si diaphragm was employed for the latter with the 3C-SiC unintentionally nitrogen doped during APCVD. Although the gauge factor of the $\mathrm{SiC}$ piezoresistors was compromised with increasing operating temperature, sensing 
capabilities up to $400^{\circ} \mathrm{C}$ have been demonstrated. Another important area of technology is $\mathrm{SiC}$ accelerometers which are particularly attractive for detecting high-g acceleration at elevated temperatures such as in aeroplane engine, military and space applications (Atwell et al., 2003; Okojie et al., 2001). Recent findings from Pakula and French have demonstrated a CMOS compatible 3D SiC capacitive accelerometer with both vertical and lateral accelerometers fabricated in the same process using PECVD SiC (Pakula et al., 2003a,b). The fully released structures are shown in Figure 11. Furthermore, SiC chemical sensors have also been investigated based on components such as SiC Schottky diode (Baranzahi et al., 1997) and microhotplate structures (Solzbacher et al., 2001). Using these devices, a combustion monitoring gas sensors for operation up to $700^{\circ} \mathrm{C}$ was obtained (Baranzahi et al., 1997). Porous $\mathrm{SiC}$ has also been used to fabricate relative humidity sensors (Connolly et al., 2002). Finally, Strokan et al. has demonstrated the possibility to use SiC-based structures to detect alpha particles and weak ionisation radiation (Strokan et al., 2003).

Figure 11 (a) SEM photo of fully processed vertical accelerometer and (b) processed lateral accelerometer

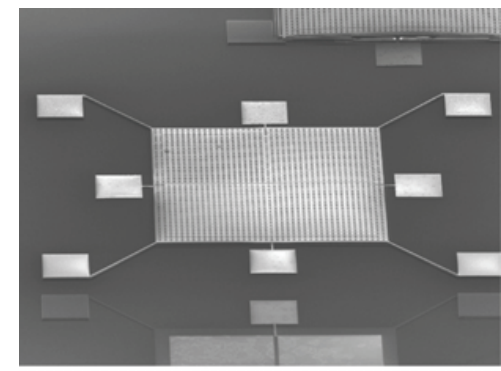

(a)

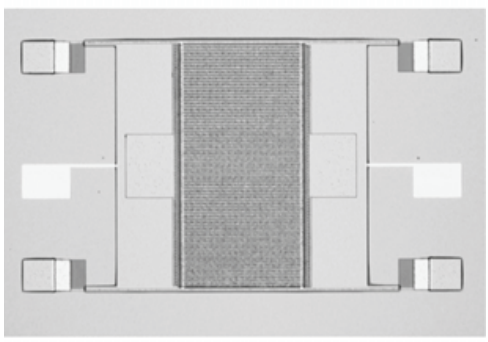

(b)

Source: Pictures courtesy of Pakula et al. (2003). DIMES, Delft University of Technology, The Netherlands.

\subsection{SiC coated MEMS}

One of the reliability issues relating to Si MEMS is unwanted wear and adhesion. Being a more robust material $\mathrm{SiC}$ shows superior tribological properties over $\mathrm{Si}$. Therefore, $\mathrm{SiC}$ cannot only be used as a structural material to realise reliable micromechanical devices such as micromotors (Yasseen et al., 2000), it can also be utilised as a coating material for Si MEMS aiming at better reliability and enhancement of device lifetime. For example, compared with similar Si devices without coating, a SiC coated fuel atomiser 
presented an improved erosion resistance for long term use and resistance to fatigue in high-temperature conditions (Rajan et al., 1998, 1999). Ashurst et al. have reported a comparative wear study for released $\mathrm{Si}$ microstructures to be coated with oxidise, antiadhesion and $\mathrm{SiC}$ coatings, respectively (Ashurst et al., 2004). Low temperature $\left(800^{\circ} \mathrm{C}\right)$ deposition from DSB precursor has been used to form a thin conformal $\mathrm{SiC}$ coating. Their results suggest that $\mathrm{SiC}$ coating provides exceptional wear resistance and significant reduction in friction on the microscale. Their findings are consistent with earlier results where 3C-SiC films showed low coefficient of friction and superior scratch/wear resistance when compared to Si materials (Sundararajan, 1998). Recent results from the same group (Gao et al., 2006) also suggests that, using SiC as a substrate material significantly reduces the in-use stiction of Si MEMS structures.

\section{Summary and prospect}

Due to its advanced material properties, $\mathrm{SiC}$ has become one of the prime candidates for MEMS operating in sever conditions. In the last few years, enormous amount of research worldwide has been conducted towards the advancements in SiC material deposition, microfabrication and realisation of applicable device prototypes. Recent progress in these areas of technology has further accelerated the advancements which are briefly reviewed in this paper. In particular, CVD techniques can now provide single crystalline, polycrystalline and amorphous $\mathrm{SiC}$ with good material quality and high throughput; essential micromachining techniques continue to progress towards better efficiency. The developments in these areas significantly contributed to the embodiment of the $\mathrm{SiC}$ MEMS devices with a range of new prototypes rapid emerging.

Despite these exciting accomplishments, from commercialisation point of view, the field of $\mathrm{SiC}$ is still in its infancy. However, companies such as FLX micro have started to introduce a commercialised SiC foundry service. To promote the realisation of cost-effective SiC MEMS, many relevant aspects still require attention. For instance, to reduce the overall cost, more efficient material growth and micromachining techniques are required. Development of IC compatible processes are advantageous for MEMS in general, effective techniques would clearly be beneficial for SiC MEMS. Furthermore, for applications in harsh environments, it is particularly important to realise the integration between SiC MEMS and electronics. Thus, the interrelated field of SiC electronics has direct impact on its MEMS counterpart. Although there are challenges and issues that still need to be addressed before we see SiC MEMS produced with high volume and low unit cost, the potential of SiC MEMS has been identified. With some technical breakthroughs already in the horizon, its real potential could be realised in the near future.

\section{References}

Ashurst, W.R., Wijesundara, M.B.J., Carraro, C. and Maboudian, R. (2004) 'Tribological impact of $\mathrm{SiC}$ encapsulation of released polycrystalline silicon microstructures', Tribology Letters, Vol. 17, p.195.

Atwell, A.R., Okojie, R.S., Kornegay, K.T., Roberson, S.L. and Beliveau, A. (2003) 'Simulation, fabrication and testing of bulk micromachined $6 \mathrm{H}-\mathrm{SiC}$ high- $g$ piezoresistive accelerometers', Sensors and Actuators A, Vol. 104, p.11. 
Baranzahi, A., Tobias, P., Spetz, A.L., Lundström, I., Mårtensson, P., Glavmo, M., Göras, A., Nytomt, J., Salomonsson, P. and Larsson, H. (1997) 'Combustion and emission formation in SI engines', SAE Technical Paper Series 972940, p.231.

Bischoff, L., Teichert, J. and Heera, V. (2001) 'Focused ion beam sputtering investigations on SiC', Applied Surface Science, Vol. 184, p.372.

Boo, J.H., Lee, S.B., Yu, K.S., Sung, M.M. and Kim, Y. (2000) 'High vacuum chemical vapour deposition of cubic $\mathrm{SiC}$ thin films on $\mathrm{Si}$ (001) substrates using single source precursor', Surface Coatings Technology, Vol. 131, p.147.

Chen, J., Scofield, J. and Steckl, A.J. (2000) 'Formation of SiC SOI structures by direct growth on insulating layers', Journal of Electrochemical Society, Vol. 147, p.3845.

Cheung, R. (2006) Silicon Carbide Microelectromechanical Systems for Harsh Environments, London: Imperial College Press.

Clavaguera-Mora, M.T., Rodriguez-Viejo, J., El Felk, Z., Hurtos, E., Berberich, S., Stoemenos, J. and Clavaguera, N. (1997) 'Growth of SiC films obtained by LPCVD', Diamond and Related Materials, Vol. 6, p.1306.

Connolly, E.J., O’Halloran, G.M., Pham, H.T.M., Sarro, P.M. and French, P.J. (2002) ‘Comparison of porous silicon, porous polysilicon and porous silicon carbide as materials for humidity sensing applications', Sensors and Actuators A, Vol. 99, p.25.

Dong, Y., Zorman, C. and Molian, P. (2003) 'Femtosecond pulsed laser micromachining of single crystalline $3 \mathrm{C}-\mathrm{SiC}$ structures based on a laser-induced defect-activation process', Journal of Micromechanics and Microengineering, Vol. 13, p.680.

Flamm, D.L., Donnelly, V.M. and Mucha, J.A. (1981) 'The reaction of fluorine atoms with silicon', Journal of Applied Physics, Vol. 52, p.3633.

Flannery, A.F., Mourlas, N.J., Storment, C.W., Tsai, S., Tan, S.H., Heck, J., Monk, D., Kim, T., Gogoi, B. and Kovacs, G.T.A. (1998) 'PECVD silicon carbide as a chemically resistant material for micromachined transducers', Sensors and Actuators A, Vol. 70, p.48.

Gao, D., Carraro, C., Howe, R.T. and Maboudian, R. (2006) 'Polycrystalline silicon carbide as a substrate material for reducing adhesion in MEMS', Tribology Letters, Vol. 21, p.226.

Hensler, R. (2002) Research Report \#GB270, MEMS Technology: Where to? Business Communications Co. (bbcresearch.com).

Hurtos, E. and Rodriguez-Viejo, J. (2000) 'Residual stress and texture in poly-SiC films grown by low-pressure organometallic chemical-vapor deposition', Journal of Applied Physics, Vol. 87, p.1748.

Jiang, L., Cheung, R., Hassan, M., Harris, A.J., Burdess, J.S., Zorman, C.A. and Mehregany, M., (2003a) 'Fabrication of $\mathrm{SiC}$ microelectromechanical systems using one-step dry etching', Journal of Vacuum Science and Technology B, Vol. 21, p.2998.

Jiang, L., Cheung, R., Brown, R. and Mount, A. (2003b) 'Inductively coupled plasma etching of $\mathrm{SiC}$ in $\mathrm{SF}_{6} / \mathrm{O}_{2}$ and etch-induced surface chemical bonding modifications', Journal of Applied Physics, Vol. 93, p.1376.

Jiang, L., Plank, N.O.V., Blauw, M.A., Cheung, R. and van der Drift, E. (2004) 'Dry etching of SiC in inductively coupled $\mathrm{Cl}_{2} / \mathrm{Ar}$ plasma', Journal of Physics D: Applied Physics, Vol. 37, p.1809.

Jiang, L., Hassan, M., Cheung, R., Harris, A.J., Burdess, J.S., Zorman, C.A. and Mehregany, M. (2005) 'Dry release fabrication and testing of SiC electrostatic cantilever actuators', Microelectronic Engineering, Vols. 78-79, p.106.

Jiang, L., Cheung, R., Hedley, J., Hassan, M., Harris, A.J., Burdess, J.S., Zorman, C.A. and Mehregany, M. (2006) 'SiC cantilever resonators with electrothermal actuation', Sensors and Actuators A, Vol. 128, p.376.

Khan, F.A., Roof, B., Zhou, L. and Adesida, I. (2001) 'Etching of silicon carbide for device fabrication and through via-hole formation', Journal of Electronic Materials, Vol. 30, p.212.

Klumpp, A., Schaber, U., Offereins, H.L., Kuhl, K. and Sandmaier, H. (1994) 'Amorphous SiC and its application in silicon micromachining' Sensors and Actuators A, Vols. 41-42, p.310. 
Krotz, G., Legner, W., Moller, H., Sonntag, H. and Muller, G. (1995) 'Silicon carbide as a mechanical material', Proceedings of the 8th International Conference Solid State Sensors Actuators - Eurosensors IX, p.186.

Lee, K.S., Park, J.Y., Kim, W.J. and Hong, G.W. (2001) 'Effect of microstructure of SiC layer on the indentation properties of silicon carbide-graphite system fabricated by LPCVD method', Journal of Materials Science Letters, Vol. 20, p.1229.

Madou, M.J. (1997) 'Fundamentals of microfabrication', Boca Raton: CRC press.

Mehregany, M. and Zorman, C.A. (1999) 'SiC MEMS: opportunities and challenges for applications in harsh environments', Thin Solid Films, Vols.355-356, p.518.

Mehregany, M., Tong, L., Matus, L. and Larkin, D. (1997) 'Internal stress and elastic modulus measurements on micromachined 3C-SiC thin films', IEEE Transactions on Electron Devices, Vol. 44, p.74.

Mitchell, J.S., Zorman, C.A., Kicher, T., Roy, S. and Mehregany, M. (2003) 'Examination of bulge test for determining residual stress, Young's Modulus and Poisson's ratio of $3 \mathrm{C}-\mathrm{SiC}$ thin films', Journal of Aerospace Engineering, Vol. 16, p.46.

Nathanson, H.C., Newell, W.E., Wickstrom, R.A., Davis, Jr., J.R. (1967) 'The resonant gate transistor', IEEE Transactions on Electron Devices, Vol. 14, No. 3, p.117.

Nguyen, C.T-C. (1997) 'High-Q micromechanical oscillators and filters for communications', Proceedings of 1997 IEEE International Symposium on Circuits and System, Hong Kong, p.2825.

Nishino, S., Powell, J.A. and Will, H.A. (1983) 'Production of large-area single-crystal wafers of cubic SIC for semiconductor devices', Applied Physics Letters, Vol. 42, p.460.

Okojie, R.S., Atwell, A.R., Kornegay, K.T., Roberson, S.L. and Beliveau, A. (2001) 'Design considerations for bulk micromachining $6 \mathrm{H}-\mathrm{SiC}$ high-G piezoresistive accelerometers', Technical Digest 15th International Conference on MEMS, p.618.

Okojie, R.S., Ned, A.A. and Kurtz, A.D. (1998) 'Operation of $6 \mathrm{H}-\mathrm{SiC}$ pressure sensor at $500^{\circ} \mathrm{C}$ ', Sensors and Actuators A, Vol. 66, p.200.

Pakula, L.S., Yang, H. and French, P.J. (2003b) 'A CMOS compatible SiC accelerometer', Proceedings of IEEE Sensors 2003, Vol. 2, p.761.

Pakula, L.S., Yang, H., Pham, H.T.M., French, P.J. and Sarro, P.M. (2003a) 'Fabrication of a CMOS compatible pressure sensor for harsh environments', Proceedings of 16th IEEE International MEMS Conference, 19-23 January, Kyoto, Japan, p.502.

Park, Y.S. (1998) 'SiC materials and devices', Semiconductors and Semimetals, Vol. 52, p.3.

Pearton, S.J. (2006) 'Dry etching of SiC', Silicon Carbide MEMS for Harsh Environments, London: Imperial College Press.

Plank, N.O.V., Blauw, M.A., van der Drift, E.W.J.M. and Cheung, R. (2003) 'The etching of silicon carbide in inductively coupled $\mathrm{SF}_{6} / \mathrm{O}_{2}$ plasma', Journal of Physics D: Applied Physics, Vol. 36, p.482.

Powell, J.A., Matus, L.G. and Kuczmarski, M.A. (1987) 'Growth and characterisation of cubic SiC single-crystal films on Si', Journal of Electrochemical Society, Vol. 134, p.1558.

Rajan, N., Mehregany, M., Zorman, C.A., Stefanescu, S. and Kicher, T.P. (1999) 'Fabrication and testing of micromachined silicon carbide and nickel fuel atomizers for gas turbine engines', Journal of Microelectromechanical Systems, Vol. 8, p.251.

Rajan, N., Zorman, C.A., Mehregany, M., DeAnna, R. and Harvey, R. (1998) 'Performance of $3 \mathrm{C}-\mathrm{SiC}$ thin films as protective coatings for silicon-micromachined atomizers', Thin Solid Films, Vol. 315, p.170.

Roper, C.S., Howe, R.T. and Maboudian, R. (2006) 'Stress control of polycrystalline 3C-SiC films in a large-scale LPCVD reactor using 1,3-disilabutane and dichlorosilane as precursors', Journal of Micromechanics and Microengineering, Vol. 16, p.2736.

Roy, S., DeAnna, R.G., Zorman, C.A. and Mehregany, M. (2002) 'Fabrication and characterization of polycrystalline SiC resonators', IEEE Transactions on Electron Devices, Vol. 49, p.2323. 
Sarro, P., deBoer, C.R., Korkmaz, E. and Laros, J.M.W. (1998) 'Low-stress PECVD SiC thin films for IC-compatible microstructures', Sensors and Actuator A, Vol. 67, p.175.

Sarro, P.M. (2000) 'Silicon carbide as a new MEMS technology', Sensors and Actuators A, Vol. 82, p.210.

Solzbacher, F., Imawan, C., Steffes, H., Obermeier, E. and Eickhoff, M. (2001) 'A highly stable $\mathrm{SiC}$ based microhotplate $\mathrm{NO}_{2}$ gas-sensor', Sensors and Actuators B, Vol. 78, p.216.

Spearing, S.M. (2000) 'Material issues in microelectromechanical systems (MEMS)', Acta Materialia, Vol. 48, p.179.

Stoldt, C.R., Carraro, C., Ashurst, W.R., Gao, D., Howe, R.T. and Maboudian, R. (2002) 'A low-temperature CVD process for silicon carbide MEMS', Sensors and Actuators A, Vols. 97-98, p.410.

Stoldt, C.R., Fritz, M.C., Carraro, C. and Maboudian, R. (2001) 'Micromechanical properties of silicon-carbide thin films deposited using single-source chemical-vapor deposition', Applied Physics Letters, Vol. 79, pp.347-349.

Strokan, N.B., Ivanov, A.M., Savkina, N.S., Strelchuk, A.M., Lebedev, A.A., Syvajarvi, M. and Yakimova, R. (2003) 'Detection of strongly and weakly ionizing radiation by triode structure based on SiC films', Journal of Applied Physics, Vol. 93, p.5714.

Sundararajan, S. (1998) 'Micro/nanotribological studies of polysilicon and SiC films for MEMS applications', Wear, Vol. 217, p.251.

Wijesundara, M.B.J., Stoldt, C.R., Carraro, C., Howe, R.T. and Maboudian, R. (2002) 'Nitrogen doping of polycrystalline $3 \mathrm{C}-\mathrm{SiC}$ films grown by single-source chemical vapor deposition', Thin Solid Films, Vol. 419, p.69.

Wise, K.D. (1998) 'Special issue on integrated sensors, microactuators and microsystems (MEMS)', Proceedings of the IEEE, Vol. 86, p.1531.

Wu, C.H., Zorman, C.A. and Mehregany, M. (2006) 'Fabrication and testing of bulk micromachined silicon carbide piezoresistive pressure sensors for high temperature applications', IEEE Sensors Journal, Vol. 6, p.316.

Xie, K., Femish, J.R., Zhao, J.H., Buchwald, W.R. and Cacas, L. (1995) 'Low damage and residue-free dry etching of $6 \mathrm{H}-\mathrm{SiC}$ using electron cyclotron resonance plasma', Applied Physics Letters, Vol. 67, p.368.

Yang, Y.T., Ekinci, K.L., Huang, X.M.H., Schiavone, L.M., Roukes, M.L., Zorman, C.A. and Mehregany, M. (2001) 'Monocrystalline silicon carbide nanoelectromechanical systems', Applied Physics Letters, Vol. 78, p.162.

Yasseen, A.A., Wu, C.H., Zorman, C.A. and Mehregany, M. (2000) 'Fabrication and testing of surface micromachined polycrystalline SiC micromotors', IEEE Electron Device Letters, Vol. 21, p.164.

Zappe, S., Franklin, J., Obermeier, E., Eickhoff, M., Moller, H., Krotz, G., Rougeot, C., Lefort, O. and Stoemenos, J. (2001) 'High temperature 10 bar pressure sensor based on 3C-SiC/SOI for turbine control applications', Materials Science Forum, Vols. 353-356, p.753.

Ziermann, R., von Berg, J., Obermeier, E., Wischmeyer, F., Niemann, E., Möller, H., Eickhoff, M. and Krötz, G. (1999) 'High temperature piezoresistive $\beta$-SiC-on-SOI pressure sensor with on chip SiC thermistor', Materials Science and Engineering B, Vols. 61-62, p.576.

Zorman, C.A., Fleischman, A.J., Dewa, A.S., Mehregany, M., Jacob, C., Nishino, S. and Pirouz, P. (1995) 'Epitaxial growth of 3C-SiC films on 4 in diam (100) silicon wafers by atmospheric pressure chemical vapor deposition', Journal of Applied Physics, Vol. 78, p.5136.

Zorman, C.A., Fu, X.A. and Mehregany, M. (2006) 'Deposition techniques for SiC MEMS', Silicon Carbide MEMS for Harsh Environments, London: Imperial College Press.

Zorman, C.A., Rajgopal, S., Fu, X.A., Jezeski, R., Melzak, J. and Mehregany, M. (2002) 'Deposition of polycrystalline 3C-SiC films on $100 \mathrm{~mm}$ diameter (100) Si wafers in a large-volume LPCVD furnace', Electrochemical and Solid State Letters, Vol. 5, p.G99. 